\title{
On the reciprocal relationship between job insecurity and employee well-being: Mediation by perceived control?
}

\author{
Tinne Vander Elst ${ }^{*}$, Anja Van den Broeck ${ }^{2,3}$, Nele De Cuyper' and \\ Hans De Witte ${ }^{1,3}$ \\ 'Research Group on Work, Organizational and Personnel Psychology, KU Leuven, \\ Belgium \\ ${ }^{2}$ Human Relations Research Group, KU Leuven, Belgium \\ ${ }^{3}$ Optentia Research Focus Area, North-West University, South Africa
}

\begin{abstract}
This study aims to explain the reciprocal relationship between job insecurity and employee well-being (i.e., emotional exhaustion and vigour) by perceived control. Building on appraisal theory and conservation of resources theory, we suggest that perceived control mediates the cross-lagged relationships from job insecurity to employee well-being, and from employee well-being to job insecurity. These hypotheses were tested using repeated-measures data (two waves) from 536 Flemish employees from different organizations and sectors. First, cross-lagged structural equation modelling analyses showed an effect from job insecurity to perceived control, and from perceived control to emotional exhaustion, so that perceived control (partially) mediated the positive cross-lagged relationship from job insecurity to emotional exhaustion. Second, we established a cross-lagged effect from emotional exhaustion to perceived control, although not from perceived control to job insecurity. Third, no cross-lagged paths were found between perceived control and vigour. This study contributes to both appraisal theory and conservation of resources theory by investigating reciprocal relationships that fit the transactional conceptualization of stress within both frameworks. Furthermore, the results of this study highlight perceived control as the process through which the stressor job insecurity impacts on employee well-being.
\end{abstract}

\section{Practitioner points}

- The current study suggests a possible theoretical explanation of the negative consequences of job insecurity for employee well-being: Perceived control accounted for the effect of job insecurity on emotional exhaustion.

- Job insecurity enhances emotional exhaustion by decreasing employees' feelings of control. Therefore, interventions providing employees with a sense of control, such as communication programmes and measures that promote participative decision-making, may provide a deterrent to this effect.

- The current study additionally adds to our knowledge of the impact of employee well-being on evaluations of the work situation: Emotional exhaustion was found to be related to reduced perceived control over the work situation.

\footnotetext{
*Correspondence should be addressed to Tinne Vander Elst, Tiensestraat 102, Box 3725, 3000 Leuven, Belgium (email: tinne. vanderelst@ppw.kuleuven.be).
} 
- Practitioners may want to invest in measures that stimulate employee well-being, for example job design. This may increase employees' perceptions of control, which then makes them less vulnerable to stressors. Additionally, by fostering both employee well-being and perceived control, practitioners may forestall a loss cycle between poor well-being and lack of control.

Job insecurity is defined as the perceived threat of losing the current job (De Witte, 2005). Particularly given the recent economic downturn, job insecurity is a cause for concern for many workers, with implications also for organizations. It is an important work stressor eliciting poor employee well-being, reflected in, for instance, feelings of anxiety and depression, burnout, and increased medical consultations for psychological distress (Dekker \& Schaufeli, 1995; Probst, 2008; for meta-analytical results see Cheng \& Chan, 2008; Sverke, Hellgren, \& Näswall, 2002). Traditionally, employee well-being is thus considered a consequence of job insecurity. More recently, scholars have argued and demonstrated that the relationship between job insecurity and employee well-being may be more complex: It may take the form of a reciprocal relationship (De Cuyper, Mäkikangas, Kinnunen, Mauno, \& De Witte, 2012). The issue of a reciprocal relationship is, however, relatively new and poorly understood in terms of underlying mechanisms.

In response, we advance perceived control as a critical mechanism accounting for the reciprocal relationship between job insecurity and employee well-being. Perceived control concerns employees' situational appraisals of their resources to deal with the threatened work situation (cf. Lazarus \& Folkman, 1984; Vander Elst, De Cuyper, \& De Witte, 2011). The mediating role of perceived control in the reciprocal relationship between work stressors, such as job insecurity, and employee well-being can be understood with reference to appraisal theory (Lazarus, 1999; Lazarus \& Folkman, 1984) and conservation of resources theory (COR; Hobfoll, 1989, 2001). The threat of job insecurity may result in reduced perceived control over the work situation, which in turn may negatively affect employee well-being and hence may evoke resource loss. Employee well-being as a personal resource may strengthen perceptions of control, which may imply reduced levels of job insecurity. Perceived control as a mediator in the job insecurity-employee well-being relationship was advanced earlier by Vander Elst et al. (2011), although in a cross-sectional study. Hence, issues related to causality, and reciprocal relationships in particular, need to be demonstrated. The current study aims to further our understanding of the explanatory role of perceived control in the reciprocal relationship between job insecurity and poor employee well-being (i.e., emotional exhaustion and reduced vigour). This complies with a transactional conceptualization of stress, in which stress is considered an ongoing process and the stressor-well-being relationship is advanced as reciprocal.

We see our contributions as follows. First, this study presents a test of key tenets of our theoretical frameworks, namely the assumption of reciprocal relationships between appraisals of the work situation (i.e., job insecurity and perceived control) and employee functioning (i.e., employee well-being) from appraisal theory, and the assumption that resource loss leads to further loss from COR. Second, this study contributes to the job insecurity literature in two ways: It elaborates on the theoretical explanations of the detrimental impact of job insecurity on employee well-being (along with studies by, e.g., De Cuyper \& De Witte, 2006; Selenko \& Batinic, 2013), and it probes (poor) employee well-being and (lack of) perceived control as possible antecedents of job insecurity. The current study thus concerns both potential consequences and drivers of job insecurity. Third, we are among the first to investigate an explanatory mechanism in the reciprocal relationship between job insecurity and 
employee well-being using a (2-wave) repeated-measures design. Such a design makes it possible to investigate whether job insecurity predicts perceived control and whether perceived control influences employee well-being, and vice versa. It thus offers a stronger test for mediation or indirect effects $^{1}$ (Cole \& Maxwell, 2003). Finally, we aim to assist practitioners in preventing job insecurity and poor employee well-being from negatively affecting each other by highlighting the importance of perceived control. Enhancing perceptions of control may break the chain linking job insecurity to poor employee well-being.

\section{Job insecurity and employee well-being}

Job insecurity is conceived as a stressor and the following characteristics are important to mention. First, job insecurity is a subjective experience: It concerns the employee's perception and interpretation of the work environment. Accordingly, job insecurity levels may be different for employees who are in the same objective situation (Klandermans \& van Vuuren, 1999). Second, job insecurity is involuntary. Job insecure employees experience a discrepancy between the perceived and the desired level of security of their current employment (Jacobson \& Hartley, 1991). Third, job insecurity primarily concerns the insecurity about one's future employment or the threat of losing one's current job (Sverke et al., 2002). Finally, although job insecurity may change over time, it is found to be a rather enduring experience (Mauno, Leskinen, \& Kinnunen, 2001). Hence, it may be considered a chronic stressor or threat appraisal (i.e., a stressor which 'may or may not be initiated by a discrete event and which persists continuously for a long time', Elliott \& Eisdorfer, 1982, p. 151).

Job insecurity has been associated with poor employee well-being (Cheng \& Chan, 2008; Sverke et al., 2002). In line with the stressor-strain perspective, most research has focused on the path from job insecurity to employee well-being. Stress theories such as appraisal theory and COR have, however, conceived stress in terms of a process and highlight the need to account for reciprocal relationships. In particular, appraisal theory (Lazarus, 1999; Lazarus \& Folkman, 1984) suggests that threat appraisals such as job insecurity may result in strain or reduced well-being. At the same time, factors tied to the person such as employee well-being may influence threat appraisals, and hence also the perception of job insecurity. Similarly, COR (Hobfoll, 1989, 2001) is built on the idea that resource loss triggers further losses. More specifically, job insecurity presents a threat to existing resources, leading to further loss, for example in the form of reduced employee well-being. This may eventually lead to a loss cycle so that reduced well-being leads to an increase in perceptions of job insecurity. Following the process conceptualization of stress, employee well-being can thus be considered both as a consequence and an antecedent of job insecurity.

We focus on work-related well-being, as it more closely relates to the experience of job insecurity as compared to general well-being, which is also influenced by factors outside one's work life (e.g., stressors in the private context or personal predispositions; Cheng \& Chan, 2008). Specifically, we selected emotional exhaustion (i.e., mental fatigue) and vigour (i.e., high levels of mental energy). These indicators are the energy-related components of burnout and work engagement, respectively (Bakker, Schaufeli, Leiter, \& Taris, 2008), and represent different, but complementary aspects of employee well-being

\footnotetext{
'The terms 'mediation' and 'indirect effect' are used interchangeably in this article (cf. Preacher \& Hayes, 2008).
} 
(Demerouti, Mostert, \& Bakker, 2010). While emotional exhaustion represents poor well-being or strain, vigour pertains to optimal functioning.

Cross-sectional studies have found a significant positive relationship between job insecurity and emotional exhaustion (De Cuyper, De Witte, Vander Elst, \& Handaja, 2010; Kausto, Elo, Lipponen, \& Elovainio, 2005) and a negative relationship between job insecurity and vigour (De Cuyper et al., 2010; Kinnunen, Mauno, \& Siltaloppi, 2010). Additionally, longitudinal studies demonstrated a cross-lagged effect of job insecurity on emotional exhaustion (De Cuyper et al., 2012; Kinnunen, Mauno, Nätti, \& Happonen, 1999), and recent evidence has also been found for a cross-lagged effect of emotional exhaustion on job insecurity (De Cuyper et al., 2012). This study expands this research, firstly by investigating the cross-lagged reciprocal relationship between job insecurity and vigour, and secondly by examining a possible explanatory mechanism of the reciprocal relationship between job insecurity and employee well-being, namely perceived control.

\section{Perceived control}

We conceive perceived control as employees' evaluation of their physical, social, psychological, and material resources to deal with the threatened work situation (cf. Lazarus \& Folkman, 1984; Vander Elst et al., 2011). Perceived control is a situational appraisal because of its reference to the current work situation, and may serve as a resource because it is helpful in dealing with stressful circumstances. It can be distinguished from control conceived as a characteristic of the employee (e.g., internal locus of control; i.e., a dispositional variable reflecting the generalized belief that a person can influence certain outcomes; $\mathrm{Ng}$, Sorensen, \& Eby, 2006) or the job (e.g., job control; i.e., 'the degree to which employees have the freedom to make decisions regarding the work assignment and their work methods'; Karasek, 1979, p. 281), or the actual practice of control (e.g., coping reactions; i.e., 'the cognitive and behavioural efforts to master, reduce, or tolerate the internal and/or external demands that are created by the stressful transaction'; Folkman, 1984, p. 843).

Our notion of perceived control relates to Bandura's (1982) concept of self-efficacy (Lazarus \& Folkman, 1987) and to job self-efficacy in particular. Job self-efficacy is specific to the job context and is defined as 'individuals' specific beliefs about their ability to exercise control over difficult job situations and successfully perform their job' (Schreurs, van Emmerik, Notelaers, \& De Witte, 2010, p. 61). Most job insecurity scholars have used general measures of (job) self-efficacy (e.g., 'I feel prepared to meet most of the demands in my job'; König, Debus, Häusler, Lendenmann, \& Kleinmann, 2010), or measures that grasp one's perceived ability to perform one's job (e.g., 'I have all the skills needed to perform my job very well'; Schreurs et al., 2010). In contrast, we respond to Bandura's call to operationalize self-efficacy so that it is specific to the domain of job insecurity.

\section{Explaining the reciprocal relationship between job insecurity and employee well-being by perceived control}

We conceive the relationship between job insecurity and employee well-being in terms of a reciprocal process, such that job insecurity affects well-being and vice versa. Perceived control may mediate these relationships. This idea can be understood alongside insights from appraisal theory and COR. 
From job insecurity to employee well-being through perceived control

Perceived control may be advanced as a possible explanation for the negative effects of job insecurity on employee well-being (Vander Elst et al., 2011). This may be grounded in appraisal theory (Lazarus, 1999; Lazarus \& Folkman, 1984). When entering a situation, individuals evaluate the stakes in that situation, which results in the 'primary appraisal' of the situation as irrelevant, benign-positive, or stressful. Stressful appraisals can then take the form of harm/loss (i.e., a damage already done), challenge (i.e., an opportunity for growth, mastery, or gain), and/or threat (i.e., a possibility of harm or loss). When individuals appraise the situation as threatening, they will evaluate their resources to cope with the demands in the situation ('secondary appraisal'). While high levels of perceived coping resources are beneficial, the perception of insufficient resources has negative consequences for well-being.

Job insecurity is likely to be perceived as threatening by workers: Job insecure workers anticipate job loss, which implies potential loss of important benefits of work, such as earning an income, social contacts, and structuring of time (De Witte, 1999; Jahoda, 1982). Furthermore, job insecure situations are characterized by the difficulty of coping with or controlling the stressful situation, as employees do not know what will happen in future (Dekker \& Schaufeli, 1995). Moreover, job insecurity largely results from unchangeable external factors, such as financial difficulties in the organization and the national unemployment rate (De Witte, 2005). Hence, following appraisal theory, after the evaluation of the work situation as job insecure, employees may evaluate their abilities to control this situation as insufficient, which may then result in reduced well-being.

A similar reasoning can be found in COR (Hobfoll, 1989, 2001), which maintains that people strive to retain, foster, and protect their resources. In COR, resources concern all objects, conditions, personal characteristics, and energies that are valuable for survival, either because they are of direct value or because they indirectly contribute to acquiring other resources. The actual loss of or the threat to such resources is considered the primary mechanism leading to strain. COR additionally states that resource loss triggers further resource loss and eventually loss cycles.

Employment is a valuable resource in many respects, not only because it provides financial stability, but also, for example, because it promotes social contact and structures time (Jahoda, 1982). Job insecurity represents a threat to this resource. As job insecure employees are unsure about what will happen and job insecurity largely results from unchangeable external factors (Dekker \& Schaufeli, 1995; De Witte, 2005), employees' investments of resources in overcoming this threat are likely to be in vain. Anticipatory coping might therefore lead to further resource depletion on the personal level, resulting in lower levels of perceived control. This in turn is a signal of resource loss and may trigger further resource losses that may eventually negatively affect employee well-being.

Initial evidence for the explanatory role of perceived control in the job insecuritywell-being relationship was provided in a cross-sectional study by Vander Elst et al. (2011). They established an indirect relationship between job insecurity and several outcomes (including psychological distress) via perceived control. Our study goes a critical step further by using a 2-wave repeated-measures design. This is important for probing cross-lagged effects, as well as for studying potential reversed causation (see below). Regarding cross-lagged effects, we hypothesize the following (see Figure 1): 


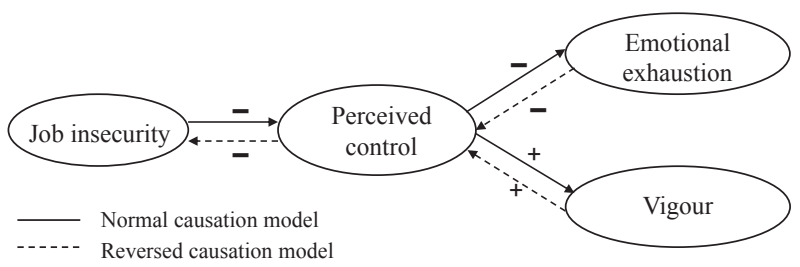

Figure I. Theoretical model.

Hypothesis 1: Perceived control mediates the relationship between job insecurity and emotional exhaustion, so that job insecurity has a negative cross-lagged effect on perceived control, and perceived control has a negative cross-lagged effect on emotional exhaustion.

Hypothesis 2: Perceived control mediates the relationship between job insecurity and vigour, so that job insecurity has a negative cross-lagged effect on perceived control, and perceived control has a positive cross-lagged effect on vigour.

From employee well-being to job insecurity through perceived control

Perceived control may also mediate the reversed relationship, that is, from employee well-being to job insecurity, based on the following arguments. First, appraisal theory (Lazarus, 1999; Lazarus \& Folkman, 1984) suggests that person variables such as personal resources (e.g., wealth, well-being and energy) may fluctuate and may influence individuals' cognitive appraisals of control ('secondary appraisal'). Individuals holding more personal resources are more likely to evaluate a specific stressful encounter as more controllable, while individuals lacking personal resources will more likely appraise the situation as difficult to control. Additionally, situational appraisals of control may influence primary appraisals regarding the meaning of a particular situation for one's goals, motives, and well-being. While challenge appraisals are more likely when employees evaluate their resources to cope with an event as sufficient, threat appraisals are more likely when employees have no sense of control.

Accordingly, we predict that vigour (a personal resource) and emotional exhaustion (indicative of reduced personal resources) will influence employees' perceptions of control. While emotional exhaustion may foster the appraisal of the work situation as difficult to control (reduction in perceived control), vigour is expected to fuel the appraisal of being able to deal with the demands at work (increase in perceived control). Next, perceived control may further influence employees' threat appraisals regarding job loss (job insecurity). Employees who perceive sufficient resources to deal with external factors that may affect their work situation are more likely to report reduced job insecurity as compared to employees with lower levels of perceived control.

Second, COR (Hobfoll, 1989, 2001) suggests that resources evolve in caravans, so that the availability of many resources initiates further resource gain, while few resources lead to a chain of losses. Individuals with limited resources may be more vulnerable to ongoing resource loss. In an attempt to protect existing resources, they no longer invest in the creation of additional resources. Protection of existing resources also consumes energy so that this leads to further resource loss. In contrast, persons endowed with many resources are less vulnerable to resource loss. They are less reluctant to invest some of their 
resources to overcome potential difficulties, so resource loss is less likely to occur. Moreover, they are more capable of resource gain, as they engage in activities that provide them with yet more resources.

Employee well-being is regarded as a personal resource in COR. Workers who feel emotionally exhausted have little energy and hence reduced resources. They are likely to evaluate their ability to control the work situation as low: They do not have a large resource pool at their disposal, which can be invested to overcome stressful situations, and they may not be willing to invest the scarce resources they have to that purpose. This, in turn, makes them perceive more stressors, such as job insecurity. In contrast, vigorous workers have high energy and many resources, which they may invest in acquiring even more resources and overcoming difficult situations at work. This likely enhances their perceptions of being in control over the work situation, which then reduces perceptions of job insecurity.

We are unaware of studies on the mediation of the cross-lagged relationships from emotional exhaustion and vigour to job insecurity by perceived control. Indirect evidence comes from research into two constructs related to perceived control - job self-efficacy and perceived employability - and their relationship with emotional exhaustion, vigour, and job insecurity. Perceived control relates to job self-efficacy as was discussed above (under 'Perceived Control'). Perceived employability, defined as employees' perceptions of available job opportunities (De Cuyper et al., 2012), induces a sense of control and mastery, and hence might equally relate to perceived control. Llorens, Schaufeli, Bakker, and Salanova (2007), for example, found work engagement (including the component of vigour) to increase future self-efficacy. Similarly, Brouwers and Tomic (2000) found emotional exhaustion to negatively predict teachers' selfefficacy in classroom management. Furthermore, Schreurs et al. (2010), for example, demonstrated the negative relationship from job self-efficacy to job insecurity, while De Cuyper et al. (2012) found employability to have a negative effect on job insecurity over time.

Based on appraisal theory, COR, and the empirical evidence presented, we thus predict (see Figure 1):

Hypothesis 3: Perceived control mediates the relationship between emotional exhaustion and job insecurity, so that emotional exhaustion has a negative cross-lagged effect on perceived control, and perceived control has a negative cross-lagged effect on job insecurity.

Hypothesis 4: Perceived control mediates the relationship between vigour and job insecurity, so that vigour has a positive cross-lagged effect on perceived control, and perceived control has a negative cross-lagged effect on job insecurity.

\section{Arguments for a repeated-measures design}

To test the hypotheses, we use a repeated-measures design, since such designs are especially suited for investigating the complex, reciprocal interplay between thoughts, emotions, and actions (Lazarus, 1999). This complexity is central to both appraisal theory and COR. First, appraisal theory states that time lags between different appraisals may vary from very short to considerably long (Lazarus \& Folkman, 1984). The relationships between job insecurity, perceived control, and well-being may require a follow-up over 
the longer term. Job insecurity is a chronic stressor and reflects event uncertainty. These characteristics may evoke a 'long, drawn-out process of appraisals and reappraisals generating conflicting thoughts, feelings and behaviours' (Lazarus \& Folkman, 1984, p. 92), in which several appraisals may mutually influence each other over longer time spans (Zourrig, Chebat, \& Toffoli, 2009). Furthermore, changes in outcomes such as employee well-being may take some time (Schwarzer, 2001), and may therefore only result in changes in situational appraisals (e.g., perceived control and job insecurity) after a longer period of time. Second, COR (Hobfoll, 1989, 2001) states that resources come in caravans, which may be extended to different situations. Hence, resource caravans are not necessarily tied to one marked-out situation or to a single time event. This implies that resources may influence each other and may further affect well-being in the long run. Changes in resources, in terms of loss or gain, may thus provoke changes in other resources and well-being over a longer period of time.

Neither appraisal theory nor COR, however, specify the time lag that should be used in repeated-measures designs. Appraisal theory does not specify the time that is necessary for certain cognitive appraisals to affect each other, and to result in certain long-term affective consequences such as employee well-being (and vice versa). Similarly, COR does not indicate how long it takes for resources to become depleted or to build resource pools. Previous studies demonstrating cross-lagged relationships between job insecurity and indicators of employee well-being have used relatively long time lags of approximately 1 year (De Cuyper et al., 2012; Kinnunen et al., 1999). We choose a time lag of 6 months, as we believe this is long enough for changes to occur in the study variables, but not so long that changes in the work environment confound the results (de Lange, 2005).

\section{Method}

\section{Data collection and respondents}

Data were collected 6 months apart in June (Time 1; T1) and December 2010 (Time 2; T2) during the economic crisis that started in 2008 in most European countries. In collaboration with a Human Resources magazine, a heterogeneous sample of 3,069 Flemish employees from different organizations in various sectors was invited to participate in an online questionnaire on well-being at work. At T1, 935 employees filled out all questions regarding the study variables (response of 30\%). At T2, these employees were again invited to fill out the questionnaire, resulting in 592 complete responses (cross-lagged response of $63 \%$, relative to T1).

Dropout analyses were conducted to test whether dropout at $\mathrm{T} 2$ could be predicted by several demographic, job-related, and organizational characteristics (i.e., age, gender, occupational status, contract type, full-time vs. part-time employment, and sector) and the T1 study variables (i.e., job insecurity, perceived control, emotional exhaustion, and vigour). A logistic regression analysis showed that dropout at T2 could not be predicted based on these variables, $\chi^{2}(10)=13.00, n s$. In addition, 56 respondents who changed jobs between the two measurements were removed from the analyses as job transitions may distort the nature of the causal relationships (de Lange, 2005). Accordingly, the total sample size was 536 employees.

The sample distribution was similar to the Flemish working population regarding age, temporary workers, and contract type (Belgian Federal Government Service of Economy, 2010): 3\% of the employees were younger than 25 years, $63 \%$ aged between 25 and 
Table I. Means, standard deviations, reliabilities (Cronbach's alpha's in parentheses) and correlations $(N=536)$

\begin{tabular}{|c|c|c|c|c|c|c|c|c|c|c|}
\hline & $M$ & $S D$ & 1 & 2 & 3 & 4 & 5 & 6 & 7 & 8 \\
\hline I. Job insecurity $\mathrm{TI}^{\mathrm{a}}$ & 2.09 & 0.88 & $(.92)$ & -.23 & .17 & -.19 & .76 & -.23 & .16 & -.19 \\
\hline 2. Perceived control $\mathrm{TI}^{\mathrm{a}}$ & 2.95 & 0.84 & & $(.83)$ & -.21 & .38 & -.17 & .64 & -.25 & .34 \\
\hline $\begin{array}{l}\text { 3. Emotional } \\
\text { exhaustion } \mathrm{TI}^{\mathrm{b}}\end{array}$ & 1.88 & 1.21 & & & $(.90)$ & -.48 & .18 & -.29 & .72 & -.41 \\
\hline 4. Vigour $\mathrm{TI}^{\mathrm{b}}$ & 4.07 & 1.24 & & & & $(.91)$ & -.19 & .38 & $-.5 \mathrm{I}$ & .78 \\
\hline 5. Job insecurity $T 2^{\mathrm{a}}$ & 1.94 & 0.91 & & & & & $(.90)$ & -.28 & .21 & -.23 \\
\hline 6. Perceived control T2 ${ }^{\mathrm{a}}$ & 2.91 & 0.95 & & & & & & $(.88)$ & -.37 & .42 \\
\hline $\begin{array}{l}\text { 7. Emotional } \\
\text { exhaustion } \mathrm{T} 2^{\mathrm{b}}\end{array}$ & 1.85 & 1.29 & & & & & & & $(.92)$ & -.54 \\
\hline 8. Vigour $\mathrm{T} 2^{\mathrm{b}}$ & 4.03 & 1.28 & & & & & & & & $(.91)$ \\
\hline
\end{tabular}

Notes. All correlations were significant at .05 level.

${ }^{\text {a }}$ Scale from I to 5 .

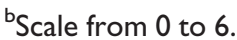

49 years, and $34 \%$ were older than 49 years $(M=43.67$ years, $S D=10.51)$, compared to $8 \%$ workers younger than 25 years, 68\% workers between 25 and 49 years, and 24\% workers older than 49 years in the Flemish working population. The sample and the Flemish population contained the same percentage of part-time workers (24\%), and about the same percentage of workers with a temporary contract ( $8 \%$ and $7 \%$, respectively). However, women were slightly over-represented in the sample when compared to the Flemish working population (58\% in the sample; $46 \%$ in the population). Blue-collar workers were under-represented in the sample ( $8 \%$ in the sample; $28 \%$ in the population). Finally, the respondents worked in both the public (36\%) and the private sector (64\% compared to $76 \%$ in the Flemish population), and $28 \%$ of the respondents went through organizational changes (e.g., mergers, restructurings, dismissals) between T1 and T2. ${ }^{2}$

\section{Measurements}

All variables were measured at $\mathrm{T} 1$ and $\mathrm{T} 2$ using internationally validated scales, which showed good reliabilities (see Table 1). The respondents were instructed to indicate the extent to which they agreed with a series of statements (job insecurity, perceived control) or the extent to which the statements applied to them (emotional exhaustion, vigour; Schaufeli \& Bakker, 2004).

\section{Job insecurity}

Job insecurity was measured with the 4-item Job Insecurity Scale of De Witte (2000), validated by Vander Elst, De Witte, and De Cuyper (2014). A sample item is 'I think I will lose my job in the near future'. The items were rated on a 5-point Likert-type scale ranging from 1 (totally disagree) to 5 (totally agree).

\footnotetext{
${ }^{2}$ More detailed information about the organizational context was not available, as the information was gathered independently of the organization for which the respondents were working.
} 
Perceived control

Perceived control was measured by means of the 3-item powerlessness scale of Ashford, Lee, and Bobko (1989). ${ }^{3}$ This scale concerns employees' perceived ability to deal with things that may affect their personal work situation and thus reflects perceived control over the threatened work situation. A sample item is 'I have enough power in this organization to control events that might affect my job'. Respondents were asked to evaluate the items on a 5-point scale from 1 (totally disagree) to 5 (totally agree).

\section{Employee well-being}

Emotional exhaustion was measured with the 5-item subscale of the Utrecht Burnout Scale (Schaufeli \& van Dierendonck, 2000). An example of an item is 'I feel totally exhausted in my job'. Vigour was measured with the 5-item subscale of the Utrecht Work Engagement Scale (Schaufeli \& Bakker, 2004). An example of an item is 'At my work, I feel bursting with energy'. The items of the emotional exhaustion and the vigour scale were rated on a 7-point scale from 0 (never) to 6 (always, every day).

\section{Covariates}

In testing the hypotheses, we controlled for different demographic, job-related, and organizational characteristics, which were found to relate to the study variables (Maslach, Schaufeli, \& Leiter, 2001; Näswall \& De Witte, 2003), namely age (years), gender $(0=$ female; 1 = male $)$, occupational status $(0=$ blue-collar and white-collar workers; 1 = managers $)$, full-time versus part-time employment $(0=$ part time; $1=$ full time $)$, contract type $(0=$ temporary; $1=$ permanent $)$, organizational change between $\mathrm{T} 1$ and T2 $(0=$ no changes; $1=$ changes $)$, and sector $(0=$ private sector; $1=$ public sector $)$.

\section{Analyses}

The hypotheses were tested by means of structural equation modelling (SEM) using AMOS 22.0. No violations regarding multi-collinearity or non-normality were found (Weston $\&$ Gore, 2006). Therefore, the maximum likelihood method was selected as the estimation procedure. To evaluate the construct validity of the study scales, we conducted confirmatory factor analysis (CFA), in which the hypothesized measurement model was tested and compared with three alternative models. The hypothesized 4-factor model included job insecurity, perceived control, emotional exhaustion, and vigour as latent factors. The first alternative model was a 3-factor model with a variable covering job insecurity and perceived control, in addition to emotional exhaustion and vigour. The second alternative model differentiated between job insecurity, perceived control, and one general well-being variable. The third alternative model was a 1-factor model in which all items were loaded on the same latent factor. In all models, the latent variables were allowed to correlate. Additionally, the discriminant validity of the measurements was evaluated using the 'average variance extracted (AVE) versus shared variance' test (Farrell, 2010). All these analyses were conducted for the T1 and the T2 scales separately.

\footnotetext{
${ }^{3}$ Ashford et al. (1989) originally presented this scale as a powerlessness (vs. control) scale. However, consistently with appraisal theory, COR, and previous studies investigating the mediating role of control in the job insecurity-outcome relationship (Vander Elst et al., 20 I I; Paulsen et al., 2005), we decided to use this scale as a measure of 'perceived control'.
} 
To exclude the possibility that temporal changes in the study variables are due to changes in the measurement model instead of true changes in the measured constructs, we investigated the invariance of the factor loadings of the measurement model across time (Brown, 2006). First, a stability or unconstrained model was constructed, in which the best-fitting measurement models from T1 and T2 were connected by including cross-lagged paths between the corresponding latent factors from T1 and T2. The error terms of the indicators from T1 were allowed to covary with their corresponding error terms from T2. In this unconstrained model, no cross-lagged equality constraints were included. Second, this stability model was compared with a constrained model in which all factor loadings were constrained to be equal over time. A non-significant improvement in model fit pointed at invariance of the constrained factor loadings. When no evidence was found for full invariance of the factor loadings, we looked for partial invariance (Byrne, 2001). We tested for the invariance of the factor loadings for each latent variable separately, and, when no full invariance of these factor loadings was found, the invariance of each factor loading of that latent factor was investigated. The equality constraints of the factor loadings that proved to be invariant were cumulatively retained, while proceeding to the test for the invariance of the other factor loadings.

To test our hypotheses, we used a cross-lagged design, in which relationships between different constructs were investigated across time after controlling for prior values of the endogenous variables (Burkholder \& Harlow, 2003). As such, we investigated predictors of across-time changes in the study constructs. This provides a stronger basis for causal inferences (Taris \& Kompier, 2006). Specifically, mediation was tested following the approach suggested by Cole and Maxwell (2003), and Taris and Kompier (2006) for 2-wave cross-lagged data (De Cuyper et al., 2012; Hakanen, Perhoniemi, \& Toppinen-Tanner, 2008). These scholars recommend a 2-step approach so that all hypothesized relationships are investigated across time. In a first series of analyses, we examined the cross-lagged relationships between job insecurity and perceived control. In a second series of tests, the cross-lagged relationships between perceived control and both emotional exhaustion and vigour were investigated. Specifically, for each series of cross-lagged tests, different models were tested and compared: (1) a stability model (with paths to test stabilities over time and synchronous relationships), (2) a normal causation model (with cross-lagged paths from T1 job insecurity to T2 perceived control in series 1 , and from T1 perceived control to T2 emotional exhaustion and vigour in series 2), (3) a reversed causation model (with cross-lagged paths from T1 perceived control to T2 job insecurity in series 1, and from T1 emotional exhaustion and vigour to T2 perceived control in series 2), and (4) a reciprocal causation model (with all cross-lagged paths described in the normal and the reversed causation model). The stability model was the baseline model to which the other models were compared. The error terms of the indicators at $\mathrm{T} 1 \mathrm{were}$ allowed to covary with the error term of the corresponding indicator at $\mathrm{T} 2$.

Different covariates were included in the structural models. For reasons of parsimony, we only controlled for those demographic, job-related, and organizational characteristics that were associated with the study variables, after regressing the study variables at T2 on these characteristics. Age, contract type, organizational change, and sector were significantly associated with job insecurity. Occupational position and contract type showed significant associations with perceived control. Hence, these variables were included as covariates in the structural models.

Following Bollen and Long (1993) and Byrne (2001), the fit of the models was evaluated using the following goodness-of-fit statistics: The comparative fit index (CFI), 
the non-normed fit index (NNFI), the root mean square error of approximation (RMSEA), and the standardized root mean square residual (SRMR). Values for CFI and NNFI indicate an excellent fit when they equal to or exceed .95. Values above .90 indicate a good fit. Values below .05 for RMSEA and values below .09 for SRMR indicate excellent fit, while values less than or equal to .08 and .10 , respectively, indicate a good fit. The $\chi^{2}$ difference test was used to compare the alternative nested models.

In the final step of the analyses, we conducted Sobel (1982) tests to formally test for mediation effects. Following Cole and Maxwell (2003) and Taris and Kompier (2006), we multiplied the cross-lagged effects (i.e., job insecurity-perceived control in series 1; perceived control-emotional exhaustion/vigour in series 2) to estimate the degree to which perceived control mediated the relationships between job insecurity and emotional exhaustion and vigour, or its reversed causal relationship. Sobel tests could only be performed when both cross-lagged effects were estimated in one of the final structural models. Note that we can only draw conclusions about partial (vs. full) mediation, as we could not directly test the significance of the direct cross-lagged relationships between job insecurity, and emotional exhaustion and vigour, due to the use of 2-wave repeated-measures data (Cole \& Maxwell, 2003).

\section{Results}

\section{Descriptive statistics}

The means, the standard deviations, and the correlations for all scales are shown in Table 1. Job insecurity $(r=.76)$, perceived control $(r=.64)$, emotional exhaustion $(r=.72)$, and vigour $(r=.78)$ showed relatively high levels of (rank-order) stabilities over time. Furthermore, the synchronous and across-time associations between the scales were as expected. Job insecurity was negatively correlated to perceived control and vigour, and positively to emotional exhaustion. Perceived control was negatively related to emotional exhaustion and positively to vigour. Finally, emotional exhaustion and vigour were negatively related.

\section{Construct validity of the measurements}

The results of the CFAs to test the measurement models are presented in the upper part of Table 2. The T1 hypothesized measurement model including four latent factors (i.e., job insecurity, perceived control, emotional exhaustion, and vigour) yielded a good fit to the data, CFI $=.95, \mathrm{NNFI}=.95, \mathrm{RMSEA}=.07, \mathrm{SRMR}=.05$. All items loaded significantly and in the expected direction on their corresponding latent factors, $M_{\text {standardized loadings }}=$ 0.81 ; Range standardized loadings $=[0.72,0.91]$. Furthermore, this hypothesized measurement model fitted the data better than the alternative 3-factor models and the 1-factor model, $\Delta \chi^{2}(3)=642.78, p<.001, \Delta \chi^{2}(3)=943.53, p<.001$ and $\Delta \chi^{2}(6)=2940.81$, $p<.001$, respectively. None of these alternative models provided a good fit. Similar results were found when testing the T2 measurement models.

In addition, the results of the AVE versus shared variance test supported the discriminant validity for the measurements at both times: For all pairs of scales, the AVE estimates of these scales were larger than the shared variance estimate. ${ }^{4}$

\footnotetext{
${ }^{4}$ Tables with detailed findings of the AVE versus shared variance test are available upon request from the first author.
} 


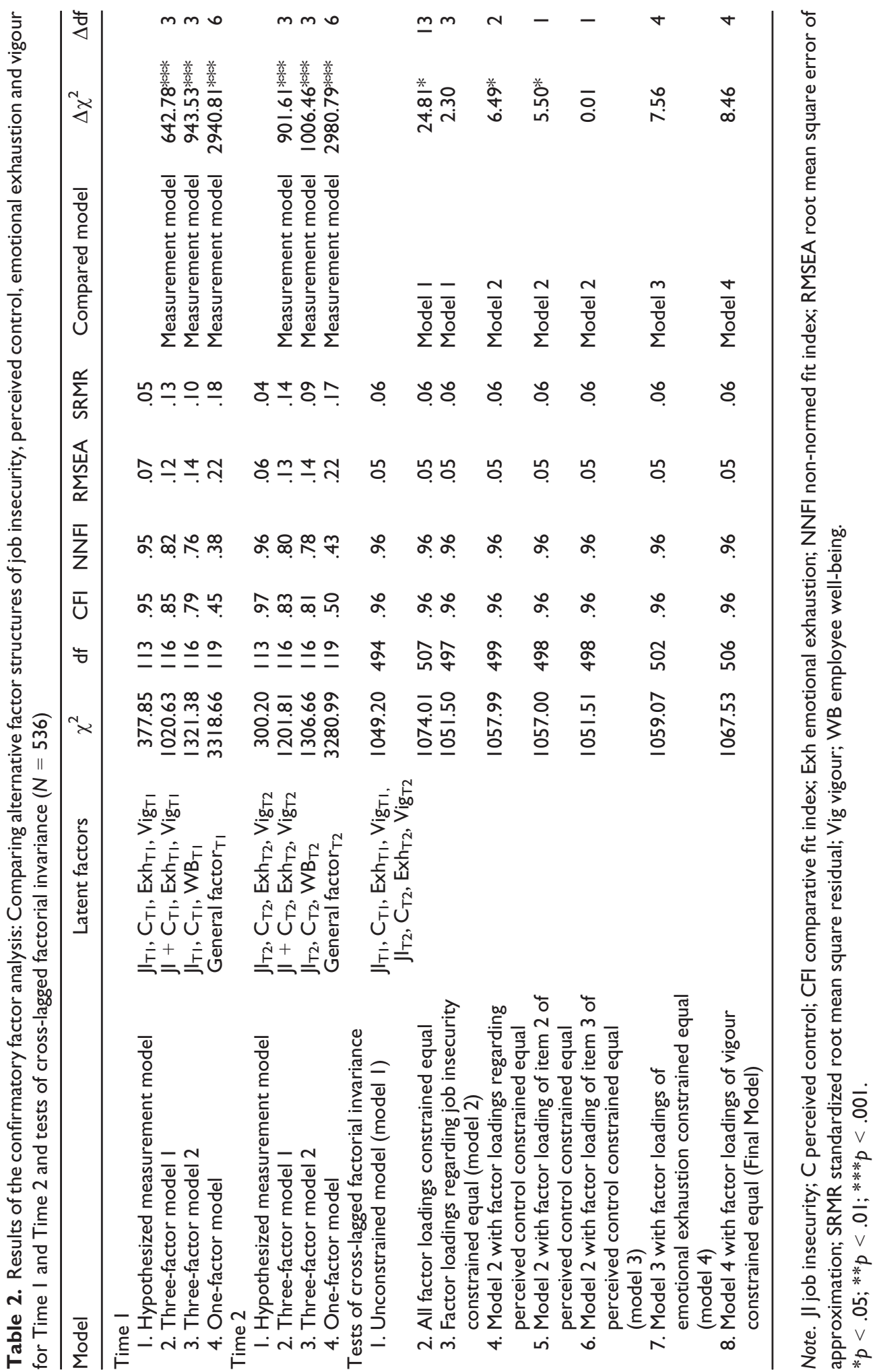




\section{Cross-lagged factorial invariance}

The lower part of Table 2 displays the results of the tests of cross-lagged factorial invariance. The unconstrained model included the best-fitting measurement models from T1 and T2, which were the hypothesized measurement models. This model showed a satisfactory fit to the data, CFI $=.96, \mathrm{NNFI}=.96, \mathrm{RMSEA}=.05, \mathrm{SRMR}=.06$.

The model in which all factor loadings were constrained to be equal across time showed a declined fit to the data when compared to the unconstrained model, meaning that no support was found for full cross-lagged factorial invariance, $\Delta \chi^{2}(13)=24.81$, $p=.02$. A step-by-step investigation of the invariance of the different factor loadings revealed that all factor loadings regarding the latent factors job insecurity, emotional exhaustion, and vigour were invariant across time. We found partial invariance of the factor loadings regarding the latent factor perceived control (the factor loading of only one item varied across time, namely 'In this organization, I can prevent negative things from affecting my work situation'). A final model in which the invariant factor loadings were constrained to be equal across time showed a satisfactory fit to the data, CFI $=.96$, NNFI $=.96$, RMSEA $=.05$, SRMR $=.06$. Overall, we may thus conclude in favour of partial cross-lagged invariance of the factor loadings.

\section{Test of the hypotheses}

In the first series of analyses to test the hypotheses, we investigated the cross-lagged relationships between job insecurity and perceived control. As shown in Table 3, the normal causation model with the association between $\mathrm{T} 1$ job insecurity and $\mathrm{T} 2$ perceived control fitted the data better than the stability model, $\Delta \chi^{2}(1)=6.72, p<.01$. The

Table 3. Results of the test of the structural models: Mediation by perceived control $(N=536)$

\begin{tabular}{|c|c|c|c|c|c|c|c|c|c|}
\hline Model & $\chi^{2}$ & df & CFI & NNFI & RMSEA & SRMR & $\begin{array}{c}\text { Model } \\
\text { comparison }\end{array}$ & $\Delta \chi^{2}$ & $\Delta \mathrm{df}$ \\
\hline \multicolumn{10}{|c|}{ Cross-lagged relationships between job insecurity and perceived control } \\
\hline I. Stability model & 410.44 & 140 & .95 & .94 & .06 & .08 & & & \\
\hline $\begin{array}{l}\text { 2. Normal causation } \\
\text { model (final model) }\end{array}$ & 403.72 & 139 & .95 & .94 & .06 & .08 & 2 versus I & $6.72 * *$ & I \\
\hline $\begin{array}{l}\text { 3. Reversed } \\
\text { causation model }\end{array}$ & 410.30 & 139 & .95 & .94 & .06 & .08 & 3 versus I & 0.14 & I \\
\hline 4. Reciprocal model & 403.45 & 138 & .95 & .94 & .06 & .08 & 4 versus 2 & 0.27 & I \\
\hline \multicolumn{10}{|c|}{ Cross-lagged relationships between perceived control, emotional exhaustion, and vigour } \\
\hline 5. Stability model & 846.47 & 328 & .95 & .94 & .05 & .07 & & & \\
\hline $\begin{array}{l}\text { 6. Normal causation } \\
\text { model }\end{array}$ & 834.46 & 326 & .95 & .95 & .05 & .06 & 6 versus 5 & $|2.0| * *$ & 2 \\
\hline $\begin{array}{l}\text { 7. Reversed } \\
\text { causation model }\end{array}$ & 821.64 & 326 & .95 & .95 & .05 & .06 & 7 versus 5 & $24.83 * * *$ & 2 \\
\hline \multirow{2}{*}{$\begin{array}{l}\text { 8. Reciprocal model } \\
\text { (final model) }\end{array}$} & 811.39 & 324 & .95 & .95 & .05 & .06 & 8 versus 6 & $23.07 * * *$ & 2 \\
\hline & & & & & & & 8 versus 7 & $10.25^{* *}$ & 2 \\
\hline
\end{tabular}

Note. CFI comparative fit index; NNFI non-normed fit index; RMSEA root mean square error of approximation; SRMR standardized root mean square residual.

$* p<.05 ; * * p<.01 ; * * * p<.001$. 
reversed causation model did not show a better fit to the data when compared to the stability model, $\Delta \chi^{2}(1)=0.14, n s$. Furthermore, the reciprocal causation model did not improve the model fit when compared to the normal causation model, $\Delta \chi^{2}(1)=0.27, n s$. Hence, the normal causation model was selected as the final model, CFI $=.95$, $\mathrm{NNFI}=.94, \mathrm{RMSEA}=.06, \mathrm{SRMR}=.08$. As expected, the relationship between $\mathrm{T} 1$ job insecurity and T2 perceived control was negative, $\beta=-.10, p<.01$ (see Figure 2). Notably, we did not find evidence of a relationship between T1 perceived control and T2 job insecurity, after controlling for stability.

In the second series of analyses, we examined the cross-lagged relationships between perceived control, and emotional exhaustion and vigour. The results are displayed in Table 3. They indicate that both the normal causation model, with associations between $\mathrm{T} 1$ perceived control and T2 emotional exhaustion and vigour, and the reversed causation model, with relationships between $\mathrm{T} 1$ emotional exhaustion and vigour and $\mathrm{T} 2$ perceived control, fitted the data better than the stability model, $\Delta \chi^{2}(2)=12.01, p<.01$ and $\Delta \chi^{2}(2)=24.83, p<.001$, respectively. The reciprocal causation model improved the model fit compared to the normal causation model and the reversed causation model, $\Delta \chi^{2}(2)=23.07, p<.001$ and $\Delta \chi^{2}(2)=10.25, p<.01$, respectively. Therefore, the reciprocal causation model was selected as the final model, CFI $=.95, \mathrm{NNFI}=.95$, RMSEA $=.05$, SRMR $=.06$. The relationship between T1 perceived control and T2 emotional exhaustion was negative as expected, $\beta=-.11, p<.01$ (see Figure 3 ). The relationship between $\mathrm{T} 1$ perceived control and $\mathrm{T} 2$ vigour was, however, not significant at the .05 level, although it was significant at the .10 level, $\beta=.07, p=.07$. Additionally, we found a significant relationship with $\mathrm{T} 2$ perceived control for T1 emotional exhaustion, $\beta=-.17, p<.001$, but not for T1 vigour, $\beta=.03$, ns.

Finally, a Sobel test demonstrated that the cross-lagged relationship between job insecurity and future emotional exhaustion (partially) went through perceived control, $z=2.03, p<.05$, which was in line with Hypothesis 1 . However, perceived control did

Time 1

Time 2

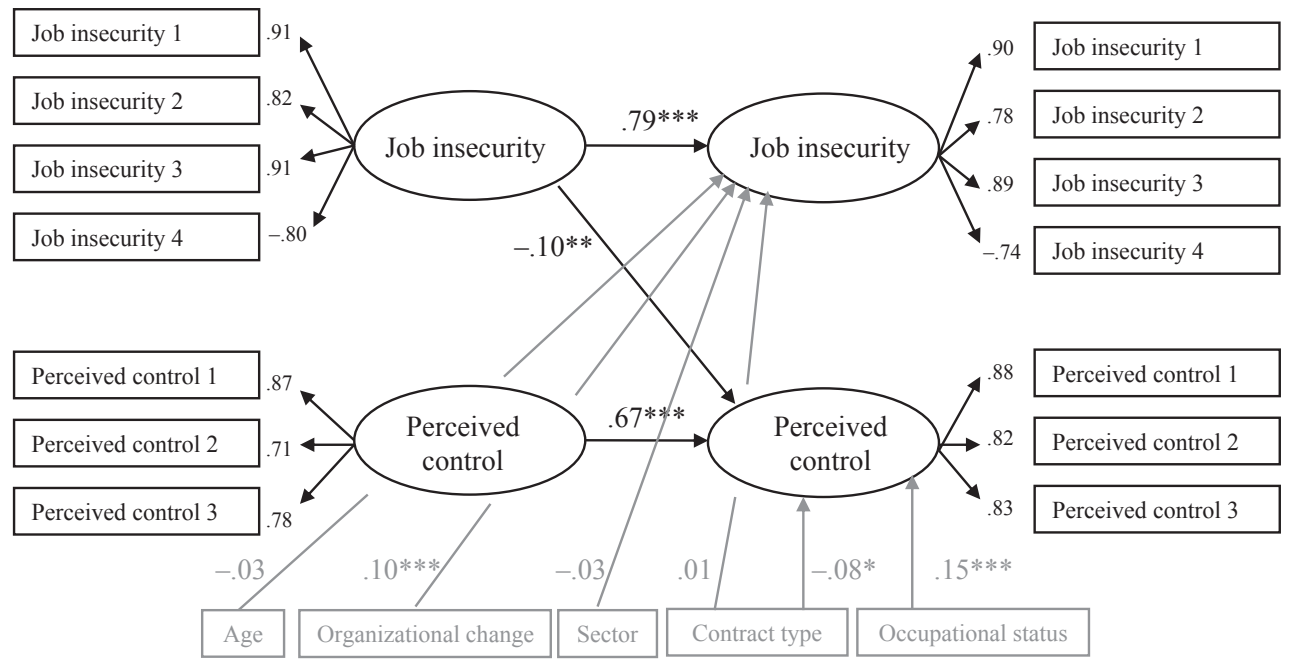

Figure 2. Final structural model with the cross-lagged relationships between job insecurity and perceived control (i.e., normal causation model).

Note. ${ }^{*} p<.05 ; * * p<.01$; ***p $<.001$. 
Time 1

Time 2

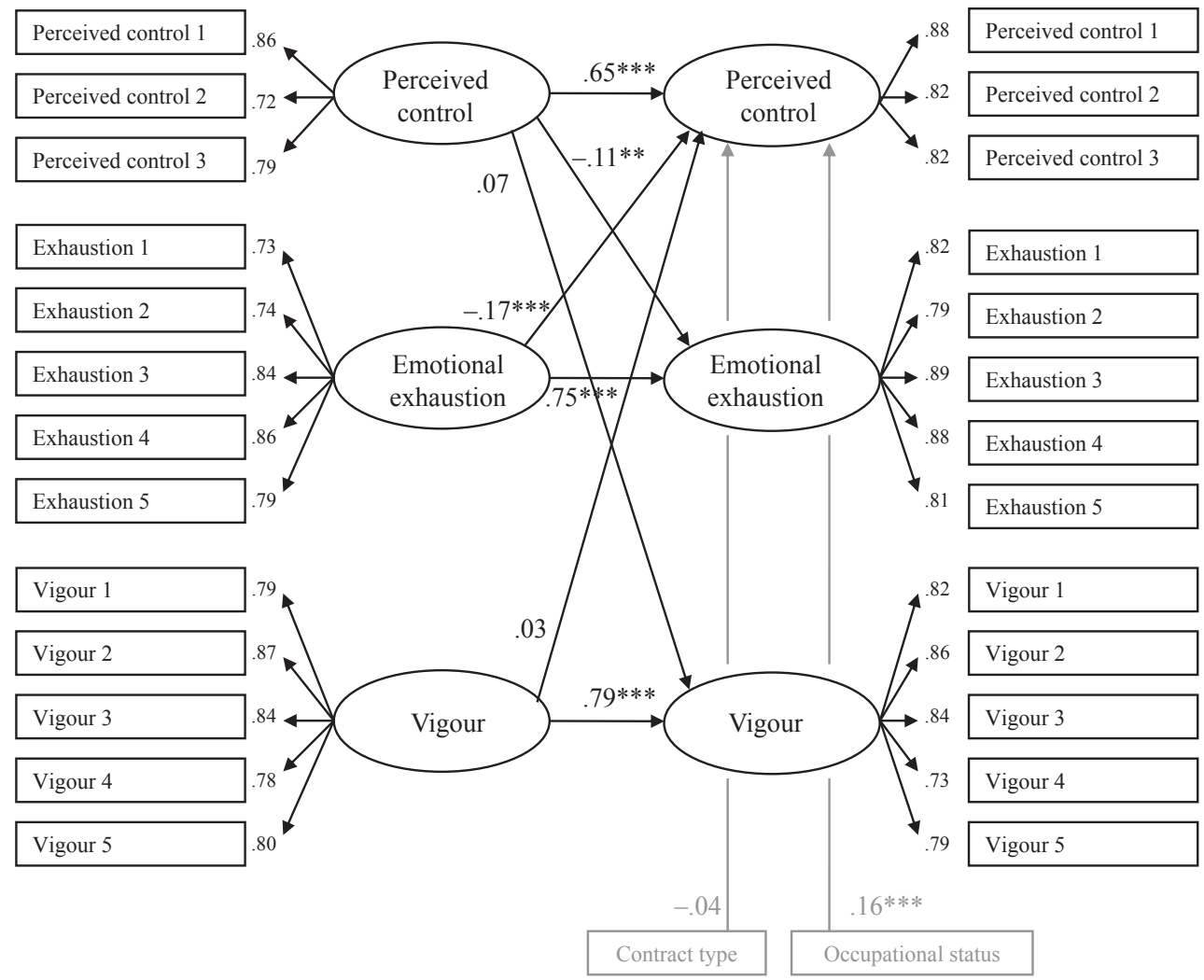

Figure 3. Final structural model with the cross-lagged relationships between perceived control, and emotional exhaustion and vigour (i.e., reciprocal model).

Note. ${ }^{*} p<.05 ; * p<.01 ; * * * p<.001$.

not account for the cross-lagged relationship between job insecurity and vigour, $z=-1.52$, ns. As we did not find evidence of the relationship between T1 perceived control and T2 job insecurity, there was no mediation effect of perceived control in the relationship between emotional exhaustion and vigour, and future job insecurity. Therefore, Hypotheses 2, 3, and 4 were rejected.

\section{Discussion}

The main aim of the current study was to investigate the indirect reciprocal relationship between job insecurity and employee well-being through perceived control. Building on appraisal theory (Lazarus, 1999; Lazarus \& Folkman, 1984) and COR (Hobfoll, 1989, 2001), we tested whether perceived control mediated the reciprocal cross-lagged relationships between job insecurity and emotional exhaustion and vigour, using a 2-wave repeated-measures design with a time lag of 6 months. To our knowledge, this study is among the first to investigate the underlying process of the job insecurity-well-being relationship using a repeated-measures design. It enhances our understanding of the explanatory factors in the reciprocal relationship between stressors and employee well-being. 
The results showed a negative cross-lagged path from job insecurity to perceived control, after controlling for initial values of perceived control and several demographic, job-related, and organizational characteristics. The more employees experienced job insecurity, the greater was their decline in perceived control half a year later. Furthermore, we found a cross-lagged relationship from perceived control to emotional exhaustion, indicating that lower levels of perceived control resulted in increased exhaustion. Perceived control (partially) mediated the cross-lagged relationship between job insecurity and emotional exhaustion. Job insecurity thus seems to lead to reduced well-being in terms of increased levels of emotional exhaustion, because job insecure employees feel they lack control over the threatened work situation. This aligns with appraisal theory and job insecurity research: Employees who appraise the job situation as insecure (i.e., a threat; 'primary appraisal') will more likely evaluate their resources to deal with this threatened work situation as insufficient over time ('secondary appraisal'). After all, job insecure employees do not know whether they will lose their job in future or not (Dekker \& Schaufeli, 1995), and job insecurity largely results from unchangeable external factors (e.g., financial difficulties in the organization; De Witte, 2005). Impaired levels of perceived control in turn reduce employee well-being in terms of increased emotional exhaustion (Lazarus \& Folkman, 1984). These findings also support COR: Job insecurity is indicative of a threat to resources and leads to further resource loss in terms of a decline in perceived control, which then results in reduced employee well-being.

The cross-lagged relationship from perceived control to vigour was not significant at the .05 level. This supports earlier research which shows that emotional exhaustion and vigour refer to different phenomena (Demerouti et al., 2010) and which shows the importance of time in the relationship between perceived control and both aspects of employee well-being. Specifically, it has been argued that emotional exhaustion reflects a physical phenomenon in terms of loss of energy emerging from an enduring process of resource loss (Maslach et al., 2001). As employees may draw on their energy reserves when experiencing a lack of a particular resource (e.g., reduced perceived control), it may take a while before all resources are depleted and employees express an increase in emotional exhaustion. By way of contrast, vigour reflects individuals' motivational energy (Schaufeli \& Bakker, 2004). The consequences of resource loss for vigour may therefore only occur in the short term, as shown in the cross-sectional relationships in this study. However, these assumptions warrant further investigation, as other scholars could establish cross-lagged relationships between job and personal resources, and work engagement (including vigour; Simbula, Guglielmi, \& Schaufeli, 2011).

Next, emotional exhaustion was shown to reduce perceived control over time. Appraisal theory and COR may account for this effect. From the perspective of appraisal theory, employees scoring highly on emotional exhaustion likely consider their resources to deal with the threatened work situation to be insufficient: They lack energy, which is an important personal resource to influence the work situation. The current results suggest that poor employee well-being may influence stress appraisals. This adds a further contribution to earlier studies that have mostly investigated the path from appraisals to well-being. From the perspective of COR, the results provide evidence of the idea that emotional exhaustion signals depleted personal resources, which then lead to further resource loss in terms of a reduction in the perceived ability to control the environment.

Contrary to expectations, however, perceived control did not influence job insecurity. Hence, perceived control did not mediate the cross-lagged relationship between employee well-being and job insecurity. Additionally, no cross-lagged relationship was found from vigour to perceived control. Although feeling vigorous might increase one's 
resources in terms of energy, this might not necessarily lead to enhanced feelings that one can control the environment.

\section{Theoretical contributions}

First, by investigating the reciprocal relationship between job insecurity (a primary threat appraisal) and perceived control (a secondary control appraisal), the current study contributes to the test of appraisal theory (Lazarus, 1999; Lazarus \& Folkman, 1984). Few studies have focused on the interplay between primary and secondary appraisals (Zourrig et al., 2009). Although appraisals may follow each other closely in time, in certain circumstances (e.g., event uncertainty and chronic stressors) appraisals may also influence each other over a longer period (Lazarus \& Folkman, 1984). This study has demonstrated a cross-lagged path from job insecurity to perceived control, suggesting that primary threat appraisals may influence secondary control appraisals over longer time periods.

Second, the study contributes to the test of COR (Hobfoll, 1989, 2001) and, more generally, attests to the conceptualization of stress as an ongoing process. Perceived control and emotional exhaustion influenced each other over time, which suggests that a negative loss cycle between perceived control and emotional exhaustion may occur.

Third, the results contribute to our knowledge of the theoretical explanations of the negative consequences of job insecurity. The results particularly emphasize the importance of the explanatory role of perceived control in the link from job insecurity to employee well-being. We showed that over time job insecurity may negatively affect employee well-being through reduced perceptions of control. The reverse was, however, not the case: Perceived control could not account for the path from employee well-being to job insecurity, as there was no cross-lagged relationship from perceived control to job insecurity.

Finally, the finding of no reciprocal relationship between job insecurity and perceived control strengthens the idea that job insecurity and perceived control are different constructs. This goes against the conceptualization of job insecurity as the 'perceived powerlessness to maintain desired continuity in a threatened job situation' (Greenhalgh \& Rosenblatt, 1984, p. 438). Following this definition, powerlessness or lack of control is considered one of the dimensions of job insecurity, and accordingly scholars have developed multidimensional job insecurity measurements including a powerlessness subscale (Ashford et al., 1989). Based on our results we, however, advocate defining both constructs separately and using separate scales for perceived control and job insecurity.

\section{Limitations and future research}

This study has some shortcomings. A first drawback concerns the choice of the time lag of 6 months. This choice may be inaccurate, possibly resulting in an underestimation of the true cross-lagged relationships. Appraisal theory (Lazarus, 1999; Lazarus \& Folkman, 1984) and COR (Hobfoll, 1989, 2001) do not specify the appropriate time intervals for investigating cross-lagged associations between the components of the stress process or the process of resource loss. Future research using different time lags may therefore provide more information about the correct length of the time lag in which job insecurity, perceived control, emotional exhaustion, and vigour influence each other (de Lange, 2005). 
Second, we used repeated-measures data with two waves. This implies that we could only draw conclusions about partial mediation, but not about full mediation, as the direct relationships between job insecurity and the well-being indicators could not be tested directly (Cole \& Maxwell, 2003). The Sobel tests conducted in this 2-wave study provide a first estimation of the strength of the mediation effects, but may represent an underestimation (Taris \& Kompier, 2006). We therefore call for future research using a 3 -wave longitudinal design to replicate our findings. Nevertheless, from a theoretical point of view, it is very plausible that perceived control is only a partial mediator, as scholars have also presented other explanations for the negative outcomes of job insecurity, such as psychological contract breach (De Cuyper \& De Witte, 2006) and deprivation of financial and social benefits of work (Selenko \& Batinic, 2013). Future research may investigate the mediating role of perceived control relative to these alternative explanations, in order to get a more complete picture of the processes accounting for the negative job insecurity outcomes.

Third, from the perspective of appraisal theory, one may criticize the operationalization of job insecurity and perceived control as situational appraisals, as these concepts were not measured with respect to a particular work situation. Although a situation may range over a longer period of time and may be relatively wide-ranging, future research may benefit from investigating the relationships between appraisals and well-being with respect to a specific, marked-out situation. Scholars may, for example, conduct studies in which respondents are asked to recall specific situations in which they perceived job insecurity, and to describe their experiences of and reactions to this demanding situation (cf. Kuppens, Van Mechelen, Smits, \& De Boeck, 2003).

Finally, although we investigated reciprocal relationships, we were not able to test the tenet of COR that the effect of repeated resource loss accelerates over time ('loss spirals'; Hobfoll, 2001), because the structure of our data (i.e., 2-wave data) does not allow for such test. It might therefore be fruitful for future research to collect within-person data in order to examine - using growth modelling - whether the reciprocal relationship between job insecurity and employee well-being via perceived control accelerates over time (von Soest \& Hagtvet, 2011).

\section{Practical implications}

Given the current development in the labour market, it seems hard to prevent all employees from feeling insecure. Hence, besides performing actions to reassure employees that they will keep their job, it is important to prevent job insecurity from resulting in poor well-being, for the benefit of employees and employers alike. Based on the finding that the effect of job insecurity on emotional exhaustion runs through perceived control, policy makers may want to introduce ways to stimulate employees' control appraisals in the work situation. Employers may, for instance, invest in clear and realistic organizational communication and in employee participation at all levels of the organization (DiFonzo \& Bordia, 1998; Vander Elst, Baillien, De Cuyper, \& De Witte, 2010).

Additionally, employers should also invest in stimulating employee well-being directly, particularly in job insecure situations, since impaired employee well-being may lead to reduced perceived control. After all, perceptions of control are important for employees in coping with stressors at work. Additionally, reduced levels of perceived control may in turn negatively affect employee well-being, resulting in a negative cycle from perceived control to well-being and vice versa. Practitioners may learn from abundant research on 
the relevance of good job design and other aspects such as organizational climate and supportive leadership to encouraging employee well-being (Van den Broeck, Van Ruysseveldt, Vanbelle, \& De Witte, 2013).

\section{Acknowledgements}

The first author's contribution was supported by a grant from the Research Foundation Flanders (FWO) for Postdoctoral Fellows (grant number $1297414 \mathrm{~N}$ ). The authors would like to thank Raf Boey of the Departement Werk en Sociale Economie (Department of Work and Social Economy) of the Vlaamse Overheid (Flemish Government) for providing us the statistics of the Flemish working population regarding age, gender, occupational status, contract type, and full-time versus part-time employment in 2010. The statistics derive from the Enquête naar de Arbeidskrachten (Labour Force Survey). The authors also would like to thank Mark Corner for language editing.

\section{References}

Ashford, S. J., Lee, C., \& Bobko, P. (1989). Content, causes, and consequences of job insecurity: A theory-based measure and substantive test. Academy of Management Journal, 32, 803-829. doi:10.2307/256569

Bakker, A. B., Schaufeli, W. B., Leiter, M. P., \& Taris, T. W. (2008). Work engagement: An emerging concept in occupational health psychology. Work and Stress, 22, 187-200. doi:10.1080/ 02678370802393649

Bandura, A. (1982). Self-efficacy mechanisms in human agency. American Psychologist, 37, 122147. doi:10.1037//0003-066X.37.2.122

Belgische Federale Overheidsdienst Economie [Belgian Federal Government Service of Economy] (2010). Enquête naar de arbeidskrachten [Labour Force Survey]. Retrieved from http://statbel. fgov.be/nl/statistieken/gegevensinzameling/enquetes/eak/

Bollen, K. A., \& Long, J. S. (Eds.) (1993). Testing structural equation models. Newbury Park, CA: Sage.

Brouwers, A., \& Tomic, W. (2000). A longitudinal study of teacher burnout and perceived self-efficacy in classroom management. Teaching and Teacher Education, 16, 239-253. doi:10. 1016/S0742-051X(99)00057-8

Brown, T. A. (2006). Confirmatory factor analysis for applied research. New York, NY: The Guilford Press.

Burkholder, G. J., \& Harlow, L. L. (2003). An illustration of a longitudinal cross-lagged design for larger structural equation models. Structural Equation Modeling, 10, 465-486. doi:10.1207/ S15328007SEM1003_8

Byrne, B. M. (2001). Structural equation modeling with Amos. Basic concepts, application and programming. Mahweh, NJ: Erlbaum.

Cheng, G. H.-L., \& Chan, D. K.-S. (2008). Who suffers more from job insecurity? A meta-analytic review. Applied Psychology: An International Review, 57, 272-303. doi:10.1111/j.1464-0597. 2007.00312.x

Cole, D. A., \& Maxwell, S. E. (2003). Testing meditational models with longitudinal data: Myths and tips in the use of structural equation modeling. Journal of Abnormal Psychology, 112, 558-577. doi:10.1037/0021-843X.112.4.558

De Cuyper, N., \& De Witte, H. (2006). The impact of job insecurity and contract type on attitudes, well-being and behavioural reports: A psychological contract perspective. Journal of Occupational and Organizational Psychology, 79, 395-409. doi:10.1348/096317905x53660

De Cuyper, N., De Witte, H., Vander Elst, T., \& Handaja, Y. (2010). Objective threat of unemployment and situational uncertainty during a restructuring: Associations with perceived 
job insecurity and strain. Journal of Business and Psychology, 25, 75-85. doi:10.1007/ s10869-009-9128-y

De Cuyper, N., Mäkikangas, A., Kinnunen, U., Mauno, S., \& De Witte, H. (2012). Cross-lagged associations between perceived external employability, job insecurity, and exhaustion: Testing gain and loss spirals according to the conservation of resources theory. Journal of Organizational Behavior, 33, 770-788. doi:10.1002/job.1800

De Witte, H. (1999). Job insecurity and psychological well-being: Review of the literature and exploration of some unresolved issues. European Journal of Work and Organizational Psychology, 8, 155-177. doi:10.1080/135943299398302

De Witte, H. (2000). Arbeidethos en jobonzekerheid: Meting en gevolgen voor welzijn, tevredenheid en inzet op het werk [Work ethic and job insecurity: Assessment and consequences for well-being, satisfaction and performance at work]. In R. Bouwen, K. De Witte, H. De Witte \& T. Taillieu (Eds.), Van groep tot gemeenschap [From group to community]. Liber Amicorum Prof. Dr. Leo Lagrou (pp. 325-350). Leuven, Belgium: Garant.

De Witte, H. (2005). Job insecurity: Review of the international literature on definitions, prevalence, antecedents and consequences. SA Journal of Industrial Psychology, 31, 1-6.

Dekker, S., \& Schaufeli, W. B. (1995). The effects of job insecurity on psychological health and withdrawal. A longitudinal study. Australian Psychologist, 30, 57-63. doi:10.1080/ 00050069508259607

de Lange, A. H. (2005). What about causality? Examining longitudinal relations between work characteristics and mental health. Ridderkerk, the Netherlands: Ridderprint BV.

Demerouti, D., Mostert, K., \& Bakker, A. B. (2010). Burnout and work engagement: A thorough investigation of the independency of both constructs. Journal of Occupational Health Psychology, 15, 209-222. doi:10.1037/a0019408

DiFonzo, N., \& Bordia, P. (1998). A tale of two corporations: Managing uncertainty during organizational change. Human Resource Management, 37, 295-304. doi:10.1002/(SICI) 1099-050X(199823/24)37:3/4\%3c295:AID-HRM10\%3e3.0.CO;2-3

Elliott, G. R., \& Eisdorfer, C. (1982). Stress and buman bealth. New York, NY: Springer.

Farrell, A. M. (2010). Insufficient discriminant validity: A comment on Bove, Pervan, Beatty, and Shiu (2009). Journal of Business Research, 63, 324-327. doi:10.1016/j.jbusres.2009.05.003

Folkman, S. (1984). Personal control and stress and coping processes: A theoretical analysis. Journal of Personality and Social Psychology, 46, 839-852. doi:10.1037//0022-3514.46.4.839

Greenhalgh, L., \& Rosenblatt, Z. (1984). Job insecurity: Toward conceptual clarity. Academy of Management Review, 9, 438-448. doi:10.2307/258284

Hakanen, J. J., Perhoniemi, R., \& Toppinen-Tanner, S. (2008). Positive gain spirals at work: From job resources to work engagement, personal initiative, and work-unit innovativeness. Journal of Vocational Behavior, 73, 78-91. doi:10.1016/j.jvb.2008.01.003

Hobfoll, S. E. (1989). Conservation of resources: A new approach at conceptualizing stress. American Psychologist, 44, 513-524. doi:10.1037/0003-066X.44.3.513

Hobfoll, S. E. (2001). The influence of culture, community, and the nested-self in the stress process: Advancing conservation of resources theory. Applied Psychology: An International Review, 50, 337-421. doi:10.1111/1464-0597.00062

Jacobson, D., \& Hartley, J. (1991). Mapping the context. In J. Hartley, D. Jacobson, B. Klandermans \& T. van Vuuren (Eds.), Job insecurity: Coping with jobs at risk (pp. 2-22). London, UK: Sage.

Jahoda, M. (1982). Employment and unemployment. A social-psychological analysis. Cambridge, UK: Cambridge University Press.

Karasek, R. (1979). Job demands, job decision latitude, and mental strain: Implications for job redesign. Administrative Science Quarterly, 24, 285-308. doi:10.1136/jech.57.2.147

Kausto, J., Elo, A.-L., Lipponen, J., \& Elovainio, M. (2005). Moderating effects of job insecurity in the relationships between procedural justice and employee well-being: Gender differences. European Journal of Work and Organizational Psychology, 14, 431-452. doi:10.1080/ 13594320500349813 
Kinnunen, U., Mauno, S., Nätti, J., \& Happonen, M. (1999). Perceived job insecurity: A longitudinal study among Finish employees. European Journal of Work and Organizational Psychology, 8, 243-260. doi:10.1080/135943299398348

Kinnunen, U., Mauno, S., \& Siltaloppi, M. (2010). Job insecurity, recovery and well-being at work: Recovery experiences as moderators. Economic and Industrial Democracy, 31, 179-194. doi:10.1177/0143831X09358366

Klandermans, B., \& van Vuuren, T. (1999). Job insecurity: Introduction. European Journal of Work and Organizational Psychology, 8, 145-153. doi:10.1080/135943299398294

König, C. J., Debus, M. E., Häusler, S., Lendenmann, N., \& Kleinmann, M. (2010). Examining occupational self-efficacy, work locus of control and communication as moderators of the job insecurity-job performance relationship. Economic and Industrial Democracy, 31, 231-247. doi: $10.1177 / 0143831 \times 09358629$

Kuppens, P., Van Mechelen, I., Smits, D. J. M., \& De Boeck, P. (2003). The appraisal basis of anger: Specificity, necessity, and sufficiency of components. Emotion, 3, 254-269. doi:10.1037/ 1528-3542.3.3.254

Lazarus, R. S. (1999). Stress and emotion: A new synthesis. New York, NY: Springer.

Lazarus, R. S., \& Folkman, S. (1984). Stress appraisal and coping. New York, NY: Springer.

Lazarus, R. S., \& Folkman, S. (1987). Transactional theory and research on emotions and coping. European Journal of Personality, 1 (3), 141-169. doi:10.1002/per.2410010304

Llorens, S., Schaufeli, W. B., Bakker, A. B., \& Salanova, M. (2007). Does a positive gain spiral of resources, efficacy beliefs and engagement exist? Computers in Human Behavior, 23, 825841. doi:10.1016/j.chb.2004.11.012

Maslach, C., Schaufeli, W. B., \& Leiter, M. P. (2001). Job burnout. Annual Review of Psychology, 52, 397-422. doi:10.1146/annurev.psych.52.1.397

Mauno, S., Leskinen, E., \& Kinnunen, U. (2001). Multi-wave, multi-variable models of job insecurity: Applying different scales in studying the stability of job insecurity. Journal of Organizational Behavior, 22, 919-937. doi:10.1002/job.122

Näswall, K., \& De Witte, H. (2003). Who feels insecure in Europe? Predicting job insecurity from background variables. Economic and Industrial Democracy, 24, 189-215. doi:10.1177/ 0143831 X03024002003

Ng, T. W. H., Sorensen, K. L., \& Eby, L. T. (2006). Locus of control at work: A meta-analysis. Journal of Organizational Behavior, 27, 1057-1087. doi:10.1002/job.416

Paulsen, N., Callan, V. J., Grice, T. A., Rooney, D., Gallois, C., Jones, E., .. Bordia, P. (2005). Job uncertainty and personal control during downsizing: A comparison of survivors and victims. Human Relations, 58, 463-496. doi:10.1177/0018726705055033

Preacher, K. J., \& Hayes, A. F. (2008). Asymptotic and resampling strategies for assessing and comparing indirect effects in multiple mediator models. Behavior Research Methods, 40, 879-891. doi:10.3758/BRM.40.3.879

Probst, T. M. (2008). Job insecurity. In C. L. Cooper \& J. Barling (Eds.), Handbook of organizational behavior (pp. 178-195). Thousand Oaks, CA: Sage.

Schaufeli, W. B., \& Bakker, A. B. (2004). Bevlogenheid: Een begrip gemeten [Work engagement: The measurement of a concept]. Gedrag \& Organisatie, 17, 89-112.

Schaufeli, W. B., \& van Dierendonck, D. (2000). Utrechtse Burnout Schaal-UBOS: Handleiding [Utrecht Burnout Scale-UBOS: Test manual]. Lisse, the Netherlands: Swets \& Zeitlinger.

Schreurs, B., van Emmerik, H., Notelaers, G., \& De Witte, H. (2010). Job insecurity and employee health: The buffering potential of job control and job self-efficacy. Work and Stress, 24, 56-72. doi:10.1080/02678371003718733

Schwarzer, R. (2001). Stress, resources, and proactive coping. Applied Psychology: An International Review, 50, 400-407.

Selenko, E., \& Batinic, B. (2013). Job insecurity and the benefits of work. European Journal of Work and Organizational Psychology, 22, 725-736. doi:10.1080/1359432X.2012.703376 
Simbula, S., Guglielmi, D., \& Schaufeli, W. B. (2011). A three-wave study on job resources, self-efficacy and work engagement among Italian school teachers. European Journal of Work and Organizational Psychology, 20, 285-304. doi:10.1080/13594320903513916

Sobel, M. E. (1982). Asymptotic intervals for indirect effects in structural equation models. In S. Leinhart (Ed.), Sociological methodology (pp. 290-312). Washington, DC: American Sociological Association.

Sverke, M., Hellgren, J., \& Näswall, K. (2002). No security: A meta-analysis and review of job insecurity and its consequences. Journal of Occupational Health Psychology, 7, 242-264. doi:10.1037/1076-8998.7.3.242

Taris, T. W., \& Kompier, M. A. J. (2006). Games researchers play: Extreme group analysis and mediation analysis in longitudinal occupational health research. Scandinavian Journal of Work, Environment and Health, 32, 463-472. doi:10.5271/sjweh.1051

Van den Broeck, A., Van Ruysseveldt, J., Vanbelle, E., \& De Witte, H. (2013). The Job DemandsResources Model: Overview and suggestions for future research. In A. B. Bakker (Ed.), Advances in positive organizational psychology (Vol, 1, pp. 83-105). Bingley, UK: Emerald. doi:10.1108/S2046-410X(2013)0000001007

Vander Elst, T., Baillien, E., De Cuyper, N., \& De Witte, H. (2010). The role of organizational communication and participation in reducing job insecurity and its negative association with work-related well-being. Economic and Industrial Democracy, 31, 249-264. doi:10.1177/ 0143831 X09358372

Vander Elst, T., De Cuyper, N., \& De Witte, H. (2011). The role of perceived control in the relationship between job insecurity and psychosocial outcomes: Moderator or mediator? Stress and Health, 27, e215-e227. doi:10.1002/smi.1371

Vander Elst, T., De Witte, H., \& De Cuyper, N. (2014). The Job Insecurity Scale: A psychometric evaluation across five European countries. European Journal of Work and Organizational Psychology, 23, 364-380. doi:10.1080/1359432X.2012.745989

von Soest, T., \& Hagtvet, K. A. (2011). Mediation analysis in a latent growth curve modeling framework. Structural Equation Modeling: A Multidisciplinary Journal, 18, 289-314. doi:10.1080/10705511.2011.557344

Weston, R., \& Gore, P. A. (2006). A brief guide to structural equation modeling. The Counseling Psychologist, 34, 719-751. doi:10.1177/0011000006286345

Zourrig, H., Chebat, J.-C., \& Toffoli, R. (2009). Exploring cultural differences in customer forgiveness behaviour. Journal of Service Management, 20, 404-419. doi:10.1108/09564230910978502

Received 2 February 2013; revised version received 25 March 2014 